\title{
Barthes y la filosofía
}

\section{Barthes and philosophy}

\author{
LUIS GARCÍA SOTO \\ Universidad de Santiago de Compostela
}

Recibido: 15/04/2020 Aceptado:03/07/2020

\section{RESUMEN}

En este texto intento analizar la relación de Roland Barthes con la filosofía, tal como aparece en sus obras. Trato de responder dos preguntas: ¿es Barthes un filósofo? ¿Es su obra filosofía? Por medio de un examen panorámico de sus escritos, muestro cómo sus obras están hechas de filosofía, clásica y contemporánea. Y señalo que el propio Barthes, al final de su carrera, se presentaba a sí mismo como filósofo.

PALABRAS CLAVE

BARTHES, FILOSOFÍA, ARISTÓTELES, ÉTICA

ABSTRACT
In this text, I try to analyze Roland Barthes's relationship with philosophy, as it appears in his own works. I try to answer two questions: is Barthes a philosopher? Is his work philosophy? Through a panoramic examination of his writings, I show how his works are made of (classical and contemporary) philosophy. And I point out that Barthes himself, at the end of his career, introduced himself as a philosopher.

\author{
KEYWORDS \\ BARTHES, PHILOSOPHY, ARISTOTLE, ETHICS
}

\section{INTRODUCCIÓN}

LA RELACIÓN ENTRE RolAnd BARTHes (1915-1980) y la filosofía es larga y compleja. Su obra está vinculada a la filosofía $a b$ initio y hasta el final,

(C) Contrastes. Revista Internacional de Filosofía, vol. XXVI No 1 (2021), pp. 83-102. ISSN: 1136-4076

Departamento de Filosofía, Universidad de Málaga, Facultad de Filosofía y Letras Campus de Teatinos, E-29071 Málaga (España) 
pero incluye componentes no filosóficos, en concreto, científicos y estéticos. Estas circunstancias se reflejan en la recepción crítica, que no siempre trata a Barthes como un filósofo. Con frecuencia su obra se adscribe a la literatura y/o a los estudios literarios, viéndose ambos como ajenos o alejados, con relación a la filosofía ${ }^{1}$. Sin embargo, frente a estas lecturas, cabe recordar que filósofos como Dufrenne (1981) y Derrida (1981), además de numerosos estudiosos, como Rubino (1984) o Marinas (2006), han situado la obra de Barthes en la filosofía. Con todo, no es nuestra intención confrontar esas lecturas, ni polemizar con unos y otros, sino dejar constancia, aunque sea minúscula, de la amplitud $^{2}$ y la diferencia de las interpretaciones, apuntando la estela en la que la nuestra se inscribe. Por nuestra parte, queremos tratar la cuestión, Barthes y la filosofía, yendo directamente a su obra y a partir del propio autor.

¿Es Barthes un filósofo, es su obra filosofía? Son cuestiones que nuestro autor tematiza, sobre todo y crecientemente, a partir de Roland Barthes par Roland Barthes $(1975)^{3}$. Y responde, ya en ese texto, afirmativamente, con matices: sí, en parte, a medias. Y además presenta su tarea futura, ya iniciada en el presente, como filosofía.

En sus palabras (Barthes 2002a, IV, pp. 652-653), su obra sería como una «chambre d' échos» y su trabajo practicar una suerte de «idéographie philosophique». Porque tomaría conceptos de otros lugares, entre ellos la filosofía, y los inscribiría, retocándolos ligeramente, en la obra propia. Que aparece, al menos en parte, no solo vinculada a la filosofía, sino integrada en el trabajo filosófico: pues él mismo practicaría una ideografía filosófica.

Unas páginas más adelante, encontramos otra función, otro papel, de la filosofía: «intertexto» (Barthes 2002a, IV, pp. 718-719). Es decir, texto (o sea, repertorio temático, conceptual, metodológico, etc.) que nutre, constitutivamente, el texto propio. Sin entrar a caracterizar este como filosófico, cosa que, como veremos, parcialmente al menos es, la filosofía aparece aquí como una fuente, que va más allá del concepto (el eco): el pensamiento filosófico informa, como nutriente, casi todas las fases, cuatro, que Barthes señala en su obra. Y la cuarta fase, «moralidad», en la que está pero que, sobre todo, indica el futuro, es nítida y netamente filosofía.

Además, en Roland Barthes par Roland Barthes, al reflexionar nuestro autor, retrospectivamente (y también prospectivamente), sobre su vida y su obra, está muy presente aquel tipo de pensamiento que Althusser (1974) llama «filosofía espontánea», es decir, aquella que se produce al meditar sobre el

1 Cfr. Pino Estivill 2018.

2 Un repertorio bibliográfico (con más de una centena de libros y una treintena de revistas) sobre Barthes: Soto 2015, pp. 125-132.

3 Siempre que sea posible, citaré por las Euvres complètes (Barthes 2002a). 
propio trabajo y, en general, sobre la experiencia de uno mismo, e ir un poco más allá.

En mi opinión, explorando esas cuatro vías (los ecos, el intertexto, la filosofía espontánea y la «moralidad») es posible hacerse una idea cabal de la relación compleja, larga y honda, de Barthes con la filosofía.

\section{Ecos}

Hay muchos ecos filosóficos por toda la obra. Y no sólo de filosofía contemporánea, como los de Sartre y de Marx, que nuestro autor menciona, junto con otros conceptos no filosóficos (Barthes 2002a, IV, pp. 652-653). De hecho, entre los cuatro términos citados, a modo de ejemplo, sólo uno es propiamente filosófico: «mauvaise foi», procedente de Sartre. Otros dos proceden del psicoanálisis: «transfert» e «imaginaire», este en concreto de Lacan. Y, finalmente, «bourgeois», de Marx. Barthes apunta cómo toma estos conceptos de los sistemas respectivos (existencialismo, psicoanálisis, marxismo) e introduce un matiz y un uso propios, netamente filosóficos: por ejemplo, crítico, ético y político («mauvaise foi») o estético y ético («bourgeois»). De los términos psicoanalíticos, indica que los lleva, del psicoanálisis, a los confines de la filosofía. Cabría añadir otros términos, filosóficos o no (por ejemplo, científicos, provenientes de las ciencias humanas y paradigmáticamente de la lingüística), que Barthes toma y retoca en su obra. Sobre cómo procede Barthes y en qué da, en qué consiste, su ideografía filosófica, son cuestiones de mucha mayor envergadura de lo que deja traslucir este fragmento, como ha mostrado y desarrollado Milner (2003), y que no abordaremos.

Por nuestra parte, indagaremos unos ecos, no citados en ese fragmento, de la filosofía clásica griega y, en concreto, de Aristóteles. Se trata de tres términos: atopía, mímesis y proaíresis. Los dos últimos poseen notable relevancia en el pensamiento aristotélico, mas no el primero. Los encontramos en la Poética (mímesis) y en la Ética a Nicómaco (atopía y proaíresis), que son textos que Barthes cita en varias ocasiones y con diversos motivos.

\section{1 Aторі́A}

Aparentemente, a tenor de algunas palabras de nuestro autor, atopía no tendría que ver con Aristóteles sino con Sócrates. En Fragments d'un discours amoureux (1977), Barthes usa el término en griego (el sustantivo atopía y también el adjetivo átopos) y lo remite a Sócrates, a su condición y posición como sujeto amado (Barthes 2002a, V, p. 65). En ese contexto, atópico vendría significando «inclasificable» y la atopía sería «ausencia de lugar». Sin embargo, Barthes usa, en textos anteriores y posteriores, atopía y atópico, con significados diferentes, sin dejar de estar asociados, o ser asociables, 
a «ausencia de lugar» e «inclasificable», y cuyo contexto no es la relación amorosa. Y ahí cabe vislumbrar, e identificar, el rastro de Aristóteles.

En Le plaisir du texte (1973), Barthes inicia y desarrolla una específica reflexión sobre la atopía y lo atópico (2002a, IV, pp. 226-227). Y vincula el concepto con la experiencia del placer y el gozo, no solo derivados del texto, de la lectura, sino en general, en términos psicológicos y con sus implicaciones sociales. Resumiendo, cabría decir que el sujeto que goza se deslocaliza: se pone, el placer lo pone, en un no-lugar. De ahí, la conexión de la atopía con la utopía, establecida a través de una experiencia posible, asequible en lo cotidiano, que interrumpe, y liga transitoriamente con lo insólito: el placer, el gozo. La referencia básica, a partir de la cual nuestro autor elabora el concepto de atopía, es la experiencia erótica. Vayamos a Aristóteles.

En la Ética a Nicómaco (1149a14), Aristóteles emplea el calificativo atópico para referirse al placer venéreo «antinatural», dicen los traductores. Quizá Barthes se inspiró en este, u otro pasaje similar, para idear la atopía. De hecho, en la base de su concepto está la sexualidad, e incluso connotada la homosexualidad, aunque no se limita a ellas y va mucho más allá, tanto en la dimensión psicológica e individual, ética, como en la implicación social y política. Inclusive, en la remisión a Sócrates, aunque se trate del amor, no dejan de estar presentes, en la atopía, como en un segundo plano, el erotismo y la homosexualidad ${ }^{4}$. Por otra parte, y a mayor abundamiento, el conocimiento filológico, y el uso, de la terminología sexual griega, por parte de Barthes, es patente en su «Primer texto», datado en 1933 pero publicado en 1974, «En marge du 'Criton'», un pastiche de Platón' (Barthes 2002a, IV, pp. 497-501).

Con estas reflexiones, no pretendo sexualizar, y menos reducir a lo sexual, el concepto de atopía, como dije vinculado al de utopía, también a la experiencia amorosa e, incluso, a la exclusión de la afectividad (Barthes 2002 b, p. 129). Lo que pretendo es mostrar el posible enraizamiento del pensamiento de Barthes en el texto, en un pequeño detalle, de Aristóteles.

\section{2 MÍMESIS}

Barthes se sirve del concepto aristotélico de mímesis, que vamos a traducir por «representación», haciendo un uso singular, que no afecta, o poco, a su significación. No innova con relación al contenido del concepto, mas sí en su aplicación. De hecho, como veremos, Barthes retiene, y usa, los dos componentes básicos de la mímesis aristotélica: la presencia y la rarefacción (podríamos decir, en términos visuales, el reflejo y la refracción) de alguna

4 «L'atopia de Socrate est liée à Eros (Socrate est courtisé d'Alcibiade)» (Barthes 2002a, V, p. 65).

5 Sobre Barthes y Platón: Milner 2003, pp. 23-24 y 67-89. 
realidad en la representación. Aristóteles sienta estas dos características básicas de la mímesis en un pasaje de la Poética (1448b4-20), que Barthes cita tácitamente en un punto, y trance, fundamental. En esa ocasión, el aspecto subrayado por Barthes es la rarefacción. Unos años después, subrayará también, y sobre todo, la presencia de lo real, o el efecto de realidad, en la mímesis. En ambos casos, se trata de la escritura, paradigmáticamente, pero no solo, de la literatura.

En Sade, Fourier, Loyola (1971), la mímesis ocupa un lugar central, tanto como aparición disociada de lo real, como por su separación de la praxis. En ambos casos, registramos la huella de Aristóteles.

Barthes interpreta la obra del escritor maldito, Sade, del socialista utópico, Fourier, y del santo jesuita, Loyola, como textos, con un trazo común: reducir lo inefable y lograr decir, hacer hablar, acerca del erotismo, la utopía y el misticismo. Nuestro autor, señala como característico en los tres autores un movimiento, no en dirección al referente (ejecutar, realizar), sino al significante (resignificar, escribir). Y, en su opinión, un movimiento similar, en dirección al significante y no al referente, debería presidir la recepción, que, no obstante, propende, dice Barthes (2002a, III, pp. 704-705), a una transmigración en la realidad, a una «co-existencia» o diseminación del texto en lo real. Aunque nuestro autor subraya que esos textos proporcionan «fragmentos de inteligibilidad»y, por tanto, prestan una inteligibilidad a lo real, esta intelección tiende a, y acaba por, traducirse en acción, en ética (en el vivir individual) y en política (en el actuar colectivo).

En ese proceder, en la recepción del texto y en su traducción en la existencia, la mímesis, entendida al modo de Aristóteles, cumple una función esencial. A propósito de Sade, y citando tácitamente la Poética, (Barthes 2002a, III, pp. $820-821$ ) rubrica el corte entre la escritura y la realidad, entre la representación y lo representado. En consonancia con Aristóteles, la mímesis, representación de lo real, modifica la percepción de lo real y, por tanto, abre, diría Barthes, un campo de experiencia novedoso, una línea de divergencia que no cabe, y no se debe, trasladar automáticamente a la realidad. En general, y en especial con Sade, Barthes (2002a, III, pp. 815-816) insiste en la diferencia - la cesura, el corte- entre lo textual y lo real... y además denuncia explícitamente la realidad que pueda haber, la que hubo y la que podría haber, detrás de esos textos.

En Leçon (1978), Barthes revaloriza la mímesis como representación, por la presencia de lo real, que contiene, y el efecto en la realidad, que desencadena. Esta revalorización de la mímesis, como representación, lo llevará a modificar su concepción de la intransitividad de la escritura (Barthes 2003, pp. 203207). También en este punto, en ese trance, confluye con Aristóteles. 
Tras una reflexión crítica sobre el poder en general y en el lenguaje, la lengua y el discurso, en particular, Barthes presenta, como alternativa, la literatura, como una manera de hacerle trampa al lenguaje. En su opinión, la literatura, por medio del trabajo sobre el significante, sería capaz de poner en jaque la aserción, los estereotipos y demás armas y ardides del código lingüístico (las lenguas) y de los sociolectos dominantes (los discursos). Barthes (2002a, V, pp. 433-438) destaca en la literatura (o escritura o texto) tres fuerzas: la mátesis, la mímesis y la semiosis. En concreto, la mímesis sería la pretensión de representar lo real, aquello que escapa al lenguaje. Persiguiendo este deseo imposible, la literatura llegaría a postularse como utopía del lenguaje. La llamada literaria a cambiar la lengua discurriría en paralelo y entrecruzándose con la llamada política a cambiar el mundo. En esta forma, como utopía del lenguaje y lenguaje de la utopía, la confrontación con el poder sería máxima y máximo también el peligro de recuperación.

Literatura, representación de lo real, utopía del lenguaje: Barthes retoma su propuesta, formulada en 1953 en Le degré zéro de l'écriture (2002a, I, pp. 222-224). Mas introduce dos modificaciones que tienen que ver con el cometido y los efectos de la literatura. Nuestro autor explora ambos, poniéndose, en los dos últimos cursos que impartirá en el Collège de France, en la posición de quien quiere escribir una novela y va a escribirla. Su pretensión será llevar la vida a la obra. Siguiendo a Proust, Barthes entiende que la escritura de la novela sería capaz de recoger y producir un «momento de verdad»: la aparición y revelación de un afecto experimentado por un sujeto, un individuo, una persona (Barthes 2003, pp. 154-161). El momento de la verdad afecta a quien escribe y a quien lee. Tipificando este afecto, Barthes, sin citarlo, alude a Aristóteles y habla de «catharsis» y de «Tragédie» (Barthes 2003, p. 159). Otra vez, y en otro pasaje fundamental, la Poética (1449b24-28). Esta referencia va más allá de la coincidencia puntual (Salazar 1993, pp. 115-116).

\section{3 PROAÍRESIS}

Barthes toma de Aristóteles, de la Ética a Nicómaco (1111b4-12a17), el vocablo proaíresis, elección, y le da un uso técnico, metodológico. Se sirve de la proaíresis como un elemento nuclear para desarrollar una herramienta analítica, en el ámbito de la semiótica y la narratología, y como un componente relevante en una filosofía de la praxis. Ambos aspectos están estrechamente vinculados, siguiéndose el segundo del primero: la recuperación del uso filosófico, del empleo metodológico técnico-científico.

Desde sus comienzos, en Le degré zéro de l'écriture (1953), Barthes otorga un papel central a la elección. Pero no se trata de la proaíresis de Aristóteles, sino de la elección existencialista, choix, tematizada por Sartre (Barthes 2002a, I, pp. 171s). Cabe conjeturar, empero, que quizá haya alguna 
influencia aristotélica en la propuesta de una «ética de la escritura» (Barthes 2002a, I, p. 222).

En $S / Z$ (1970), Barthes realiza un análisis e interpretación de un relato completo: Sarrasine, una novela breve de Balzac. Propone, como herramientas de lectura, cinco códigos. Uno de ellos es el código «proairético» o de las acciones. Le da nombre, explícitamente, a partir de la proaíresis, la elección, en la terminología de Aristóteles (Barthes 2002a, III, pp. 132-133). La elección es el nudo, la inflexión, que permite pasar de una acción a otra $y$, por tanto, relacionarlas y articularlas en secuencias, cursos y series de acciones. La lógica, la regla de funcionamiento, va a ser también de raigambre aristotélica: la empiria, lo verosímil (Barthes 2002a, III, pp. 289-290).

A pesar de partir de la proaíresis, Barthes no remite la acción a un sujeto, sino a la lógica (esas reglas) del discurso. No olvidemos que se trata de proponer una metodología para analizar un relato y, en general, los relatos. Por ese mismo motivo, debemos entender que esa exclusión (del sujeto al que cabría atribuir una acción, producto de su decisión) es metodológica. En otras palabras, en un relato, la acción y sus concatenaciones no cabe remitirlas, o solo parcialmente, a los personajes, a su capacidad individual de decisión y/o a una posible psicología como personas. Para entender y explicar las acciones es necesario encuadrar su lógica en la del relato entero, de la que dan cuenta, además del código proairético, otros códigos. Uno de ellos, el código hermenéutico, las reglas y procedimientos de resolución del enigma en torno al cual giran las acciones, permite restituir, de una manera peculiar, el lugar y la función del sujeto en el curso de las acciones. De hecho, el código hermenéutico ( $\mathrm{y}$ no solo este) obliga a recolocar la subjetividad en la proaíresis.

Según Barthes (2002a, III, pp. 294-295), el código hermenéutico da cuenta de la formulación, el tratamiento y la resolución del enigma. Este es el tema que constituye el núcleo y motor de la narración, el relato y la lectura: i.e., de las decisiones del autor, de los personajes y del lector. Subrayemos que nuestro autor, en $S / Z$, plantea la cuestión en términos, digamos, heurísticos (descubrir la verdad) y no pragmáticos (conseguir un objetivo). Ambas perspectivas no son incompatibles, y de hecho se superponen. La decisión, la proaíresis, se orienta por la búsqueda de la verdad, a la cual, sin duda, está asociada la consecución de un objetivo. En otras palabras, la acción contemplada es teleológica, y no exclusivamente estratégica. En la novela de Balzac interpretada por Barthes, las personas, como los hechos y las cosas, son objeto de cálculo. Pero la subjetividad no resulta completamente cosificada. El límite, quizá exiguo, lo pone la proaíresis, la capacidad de decisión, vinculada al interés por la verdad (Barthes 2002a, III, p. 297). 
Pensemos, por un momento, que Barthes no está hablando de una ficción literaria, sino de una historia real: tendríamos ante nuestros ojos una filosofía de la praxis. De cuño aristotélico, basada y centrada en una concepción teleológica, de la decisión y la acción, en parámetros similares, y no ajenos, a la Ética a Nicómaco. Barthes dará ese paso años más tarde.

\section{INTERTEXTO}

En segundo lugar, la filosofía como intertexto, como nutriente esencial del texto propio: no diré que es el principal intertexto, pero casi. Está presente, y marca decisivamente, las cuatro «fases» que nuestro autor distingue en su recorrido, distinguiendo cuatro «géneros» y ejemplificando con algunos libros (Barthes 2002a, IV, pp. 718-719). Con la perspectiva de la obra completa, creo que se puede mantener esa periodización, ${ }^{6}$ que nuestro autor establece a la altura de 1975 e intuyendo por donde irá su trabajo, que concluye en 1980. Teniendo en cuenta los estudios posteriores sobre la obra de nuestro autor, cabría redenominar las fases, precisar los años y recolocar algún título. Así, cabría denominarlas crítica (1953-1964), ciencia (1964-1970), estética (1970-1975) y ética (1975-1980). Algunas de estas denominaciones fueron empleadas, alternativamente, por el propio Barthes, como estética (Barthes 2010, p. 278) y, según veremos, ética (Barthes 2002b, p. 184). Son rótulos más generales y más precisos, que los «géneros» (mitología social, semiología, textualidad, moralidad) que en 1975 emplea nuestro autor. Identifican perfectamente, con las salvedades oportunas, cada uno de los períodos.

Veamos los intertextos, los repertorios temáticos y metodológicos, que, según Barthes, nutren, en relación dialéctica e interacción dialógica, su propio texto.

En la primera fase, la crítica, son fundamentales Sartre y Marx. Junto, con ellos, Brecht, escritor y ensayista. En la segunda, la ciencia, no figura como intertexto la filosofía. Barthes apunta un único nombre: Saussure. Recordemos, sin embargo, que la labor científica de Barthes, como semiólogo, está asociada al estructuralismo, que es además una posición filosófica, con la cual nuestro autor no solo mantiene una estrecha relación, sino que es uno de sus teóricos y estandartes (Barthes 2002a, II, pp. 466-472). En la tercera fase, la estética, reaparece la filosofía: entre otros no filósofos (pero no ajenos a la filosofía: Sollers y Lacan), figuran Kristeva y Derrida. Y en la última, la ética, consta en solitario Nietzsche, cuyo nombre Barthes escribe entre paréntesis, para indicar que, más bien, piensa en solitario y por sí solo... «como filósofo», añado por mi parte.

6 Cfr. Moriarty 1991. 
Cuando Barthes establece en su obra estas fases, está comenzando la que será la última. Titubea en el nombre: «moralidad», dice con matices. Atendiendo a sus escritos posteriores, podemos denominarla ética. Y, en ella, Sartre representa un papel fundamental. De hecho, Sartre acompaña a Barthes de principio a fin, desde el primer libro, en 1953, al último, en 1980.

Esta relación de filósofos, y entre ellos una filósofa, Kristeva, da idea de la importancia que, en la obra de nuestro autor, posee la filosofía como intertexto. Además, la filosofía en general y sin nombres concretos, o con nombres variados, representa un intertexto fundamental. Uno de esos nombres sería Aristóteles. Que además, a justo título, podría formar parte del intertexto explícito, de la relación colacionada por nuestro autor.

\section{1 LA FILOSOFÍA EN GENERAL}

La presencia, e influencia, de la filosofía es mucho más visible en los cursos que en los libros y artículos. En estos, Barthes tiende a desarrollar su propio pensamiento, citando lo imprescindible, más de una vez de modo tácito. Sin embargo, en los cursos, inclusive aquellos que dieron lugar a libros, la presencia e influencia de la filosofía son nítidas y marcadas.

Como ejemplo de notable conjunción y profusión de componentes filosóficos recordaré el curso sobre Le neutre, impartido en 1977-78. Barthes (2002c, pp. 25-27) comienza su disertación presentando el «intertexto», el flujo textual del que se sirvió para preparar, para articular y desarrollar, el curso. Entre los materiales (de la lingüística al derecho), predominan los textos de pensamiento filosófico, sea este más o menos puramente filosófico (Bacon, Pascal, Vico, Rousseau, De Maistre, Fichte, Hegel, Benjamin, Bachelard, Cioran) o filosófico-místico (Silesius, Boehme, Eckhart, Swedenborg) o filosófico-literario (Blanchot). Hay también una más que notable presencia del pensamiento oriental, el zen ${ }^{7}$ y el tao (Barthes 2002c, pp. 222-233). Además, en esas páginas, encontramos episodios de la historia de la filosofía (los sofistas, los escépticos, especialmente Pirrón,...) y apuntes de las biografías de esos filósofos (de la mano de Diógenes Laercio, con matizaciones de pensadores y estudiosos posteriores, como Hegel y Kojève) y de algún otro (como Espinosa). Es un ejemplo, significativo, de la relevancia de la filosofía, aunque no siempre el aporte filosófico sea tan abrumador.

El asunto de este curso es el deseo de neutralidad (Barthes 2002c, pp. 3840). Defiende la neutralidad, frente al conflicto, como una salida provisional.

7 Desde antes, el zen forma parte integrante de su pensamiento. En L'empire des signes (1970), acusa recepción y se torna objeto de reflexión (Barthes 2002a, III, pp. 403-415). Años después, en el curso 1978-79, retoma y prosigue esas reflexiones: «De la vie à l'œuvre» (Barthes 2003, pp. 53-136). 
No es la solución, pero sí una vía para ponerse en condiciones, y poner las condiciones, para su resolución. Frente a las oposiciones paradigmáticas, en las que se afirman o lo uno o lo otro, la neutralidad pretende encontrarse en un punto intermedio e intermediario: hallar el grado cero, de ni lo uno ni lo otro, o, inclusive, el término complejo, de lo uno y lo otro (Barthes 2002c, pp. 3133). Reconocemos en este planteamiento al Barthes lingüista, que busca, como solución, una posición ética. Nuestro autor explora situaciones y opciones varias. En su propuesta personal, tiene gran relevancia el escepticismo griego, expresa y singularmente Pirrón, interpretado por Hegel (Barthes 2002c, pp. 251-256). Para pronunciarse, y hay que hacerlo, muchas veces, solo cabe confiarse a la certeza, que vale para guiarse uno mismo, realizando, al albur de las circunstancias, drásticas correcciones en el rumbo trazado. Posicionarse lleva a dar bandazos. De ahí, la conveniencia de matizar los extremos y de mantener abierta la vía de la neutralidad. Con la postulación de lo neutro y la exploración de la neutralidad, Barthes, en sus propias palabras (2002c, p. 227), no pretende «revisar» sino «afinar» la noción de «compromiso» de Sartre.

\section{2 Aristóteles}

El papel de Aristóteles en Barthes va más allá de proporcionar unos conceptos, aunque algunos de estos, como mímesis y proaíresis, adquieran gran relevancia en su pensamiento, sea por sí mismos sea también por sus implicaciones. Es decir, por su función singular y como núcleo o germen de una temática en el pensamiento de Barthes. En nuestra opinión, cabe proponer a Aristóteles como intertexto, $\mathrm{y}$, precisamente, en aquella fase, que llamamos científica, en la que Barthes cultiva, como género, la semiología y no señala ningún filósofo, ninguna filosofía, como intertexto.

En aquellos años, Barthes investiga la retórica clásica, dedicándole su práctica docente en el curso 1964-65. El producto de esta investigación es el texto «L'ancienne rhétorique» (1970), que originalmente es un largo artículo y que en las traducciones, en más de una lengua, aparece como libro. Así lo recoge Barthes, como libro en la traducción italiana, al hacer inventario en Roland Barthes par Roland Barthes (2002a, IV, pp. 755).

$\mathrm{Su}$ estudio consta de dos partes: una aproximación diacrónica, sobre la historia de la retórica, y una aproximación sincrónica, acerca de la estructura de la retórica. En ambas partes, tiene un protagonismo especial, y esencial, Aristóteles, su retórica, entendida en sentido amplio, agregando Retórica y Poética (y algún otro texto aristotélico) e incluyendo sus recepciones (Barthes 2002a, III, pp. 535-536). En su opinión, la obra del estagirita impregna el desarrollo y el imperio de la retórica, sus mutaciones, su extinción e inclusive su pervivencia.

Para Barthes, Aristóteles proporciona el núcleo conceptual de la retórica, 
no siempre ni igualmente recogido entre los tratadistas. Su pensamiento conoció varias recepciones, que marcan la suerte de la retórica: la primera, la latina, de Cicerón a Quintiliano, de carácter sistemático; la segunda, la medieval, con dominancia de la Lógica; la tercera, la renacentista, por el descubrimiento de la Poética. A través de la preceptiva y canónica poéticas, la retórica imperará sobre la literatura hasta el romanticismo. Como tal, la retórica tendrá un lugar importante en la enseñanza, extinguiéndose con el desarrollo del aparato escolar, la proliferación de las materias de ciencias y, sobre todo, la mutación de las disciplinas de letras. De todas maneras, pervivirá en la cultura letrada popular y de ahí pasará, en el siglo XX, a la comunicación de masas en la sociedad occidental contemporánea.

Al abordar la arquitectura conceptual y temática de la retórica, Barthes muestra su paralelismo y persistencia en la cultura demasas. Señala cómo ambas, retórica aristotélica y cultura de masas, toman como patrón la «verosimilitud», lo verosímil, aquello que parece posible al nivel del público, según el sentido común y al amparo de la opinión corriente (Barthes 2002a, III, p. 537). Mas no se queda en el tenor general y, en ese paralelismo, reiteradamente desciende a lo concreto: razonamiento público persuasivo (deductivo, al modo del entimema, e inductivo, siguiendo el exemplum $)^{8}$, desde el discurso político al mensaje publicitario, pasando por los productos artísticos como películas y novelas, sentimientos del auditorio y psicología del público (concepción de las pasiones como fragmentos de lenguaje preformados $)^{9}$.

Barthes, siguiendo también a Aristóteles, vincula la cultura mediática y masiva con la democracia occidental contemporánea. Merece la pena resaltar esta observación sobre la política de Aristóteles: «c'était, on le sait, une politique du juste milieu, favorable à une démocratie équilibrée, centrée sur les classes moyennes et chargée de réduire les antagonismes entre les riches et les pauvres, la majorité et la minorité» (Barthes 2002a, III, p. 537). Hasta tiempos recientes, e incluso hoy, no es frecuente situar en la democracia la pieza clave de la concepción aristotélica de la política ${ }^{10}$.

Al concluir su estudio, Barthes insiste en subrayar la actualidad de la retórica antigua. A su entender, quedan rasgos de ella, la mayoría desapercibidos e incluso desconocidos, en la literatura, en la enseñanza y, en general, en las prácticas lingüísticas. Y, por otra parte, la cultura de masas es, en su opinión, absolutamente deudora de la retórica aristotélica, de la cual está impregnada y embebida. El aristotelismo, en consecuencia, sería una magnífica herramienta

8 Cfr. Barthes 2002a, III, pp. 568-574.

9 Cfr. Barthes 2002a, III, pp. 584-585.

10 Cfr. Aubenque (1993, p. 262): «la réhabilitation de la démocratie n'est pas chez Aristote une thèse circonstancielle et isolée, mais se rattache à des thèses essentielles de sa philosophie»». 
para el análisis y también para la crítica de la cultura occidental masiva contemporánea (Barthes 2002a, III, pp. 599-600) ${ }^{11}$.

En esa tarea, está implicada la literatura. Y ahí tiene un papel también Aristóteles. Lo vemos en las principales contribuciones de Barthes a la narratología. Entre las aportaciones de la etnología, la antropología y la semiótica, nuestro autor sitúa a Aristóteles, «père de l'analyse structurelle des œuvres» que forja «la science de l'action»(Barthes 2002a, III, p. 964), relevante para un análisis e interpretación de la «acción» (en literatura), congruente con los planteamientos científicos contemporáneos (Barthes 2002a, II, p. 849).

\section{FILOSOFÍA ESPONTÁNEA}

Llamo filosofía espontánea a aquel pensamiento que se genera al reflexionar y posicionarse acerca del trabajo y la experiencia propios: un pensamiento que pretende ir algo, un poco, más allá y que explícitamente se vincula a la filosofía. Cuando en 1975 se publica Roland Barthes par Roland Barthes, nuestro autor se considera un filósofo, aunque no lo declare. O lo haga con titubeos. Quizá porque se tiene por un filósofo espontáneo. Más adelante, llegará a definirse como filósofo, aunque su filosofía no se refleje, o no siempre, en sus escritos ${ }^{12}$. Sin embargo, a pesar de esta declaración, en esas fechas, 1978, sus escritos sí son filosofía.

Por ahora, intentaré caracterizar su filosofía espontánea recurriendo a la auto-reflexión sobre su vida y su obra que encontramos en Roland Barthes par Roland Barthes (1975). Señalaré algunos rasgos que, como se verá, vienen de antes y van más allá de ese texto. Como sucede con otros libros suyos, también este fue precedido de una investigación y una docencia, llevadas a cabo en el seminario de 1973-74: Le lexique de l'auteur (Barthes 2010). Como en los otros casos, solo una parte de lo trabajado pasó a la versión final en libro. Estos materiales, inéditos hasta 2010, contienen valiosas informaciones. Por ejemplo, en un fragmento no publicado, dice de sí mismo: «S'il était meilleur philosophe» (Barthes 2010, p. 317).

El interés personal de Barthes por la filosofía viene de muy atrás: lector convicto de Nietzsche en la juventud (Calvet 1990, p. 54), formado

11 Recordemos que una buena parte del trabajo de Barthes se había centrado, y seguirá haciéndolo, en realizar un análisis y una crítica de la cultura de masas occidental contemporánea. Pensemos, por ejemplo, en Mythologies (1957): reflexiones, análisis y crítica, sobre los acontecimientos, las figuras, los medios, los espectáculos, la publicidad, etc., realizadas al hilo de la actualidad entre 1954 y 1956 (Barthes 2002a, I, pp. 673-870).

12 «Mais, s'il y a un mot qui désignerait bien ce qui ce passe en moi, et non dans mes écrits, ce serait le mot 'philosophe', [...] Ce que je fais en moi, c'est de philosopher, de réfléchir sur ce qui m'arrive» (Barthes 2002a, V, p. 549). 
en filología clásica, habría lamentado no hacer los estudios universitarios de filosofía (Samoyault 2015, p. 103). Desde esa época, la filosofía tiene una notable importancia en su vida personal (Barthes 2010, p. 323). A la altura de 1975, nuestro autor hace balance. Resaltaré lo más significativo.

En mi opinión, cuatro serían los componentes de su filosofía espontánea: utopismo, hedonismo, contractualismo, preferencialismo. Algunos de estos rasgos son casi evidentes, pues Barthes los reitera y sitúa en un primer plano: la utopía, el placer. Son, además, rasgos bien patentes, en general, a lo largo de su obra. No sucede lo mismo, con los otros dos. El propio Barthes (2010, p. 203) califica el contrato como «iceberg», importante sobre todo en su pensamiento personal. Por mi parte, selecciono el preferencialismo, por las interrogantes que abre y, sobre todo, los matices que presta a los otros rasgos. A mayores, el contractualismo y el preferencialismo son trazos, casi siempre, pasados por alto en las interpretaciones del pensamiento de Barthes.

\section{1 UTOPISMO}

Contra lo que cabría esperar, después de la vindicación de la atopía, un par de años antes, en Le plaisir du texte (Barthes 2002a, IV, p. 236), la utopía constituye una referencia constante y medular en Roland Barthes par Roland Barthes (Barthes 2002a, IV, pp. 629, 653-655). Un elemento importante de esta utopía, germinal y fundador, es el marxismo ${ }^{13}$. Con este, mantiene Barthes una relación peculiar: remota, constante y distante (Calvet 1973, pp. 147-160). Lo que subscribe ${ }^{14}$, desde sus inicios en Le degré zéro de l'écriture (1953), es el utopismo marxista o el marxismo utópico. Y, más adelante, en Sade, Fourier, Loyola (1971), recupera el socialismo utópico: la utopía anarquista. Y no admitirá el marxismo sino es vinculado a la utopía (Barthes 2010, p. 279). Para caracterizar la utopía barthesiana, vale recurrir a Marcuse, un filósofo que conoce y valora la obra de nuestro autor (Marcuse 2007, pp. 87, 103-106). Siguiendo a Marcuse, podemos decir que no se trata del marxismo soviético, sino de la utopía que hay que realizar ya... como aquello que del texto de Fourier, diría Barthes, dice en 1971, puede y debe transmigrar en nuestra vida (2002a, III, pp. 704-705). Cabe vincular la utopía con lo que nuestro autor llama el «arte de vivir» burgués (Barthes 2002a, IV, pp. 625, $630,639)$, poniendo como ejemplo la vida otrora en Bayona $\mathrm{y}$, dentro de la casa, «el té» (Barthes 2002a, IV, p. 600). Sin embargo, en Roland Barthes par

13 Contra una tendencia corriente, signo de los tiempos desde las últimas décadas del siglo pasado, entendemos, como Stafford (2015, pp. 151-152), que la relación con el marxismo no debe minimizarse o soslayarse. Cfr. «Roland Barthes Dialectician? In the Final Instance?» (Stafford 2017, pp. 97-120).

14 Un momento álgido: la polémica con Camus (Roger 1986, pp. 262-278). 
Roland Barthes, nuestro autor no incorpora la reflexión, llevada a cabo en el seminario, sobre el «arte de vivir» (Barthes 2010, pp. 209-215): remite el concepto a Brecht, mostrando sus matices e implicaciones éticas y políticas, vincula el arte de vivir con la historia (el pasado) y propone una exploración prospectiva, refiriéndose explícitamente a Marcuse (acerca de la necesidad y el deseo) y asociando arte de vivir y utopía.

\section{2 HeDONISMO}

Por lo menos desde L'empire des signes (1970), el placer representa un componente básico o central (Reckert 1982, pp. 57-66). En Le plaisir du texte (1973), hallamos una formulación paradigmática. Desde Epicuro, Barthes recoge la tradición hedonista: el placer como guía de conducta, como criterio de elección, como experiencia de felicidad. Tal vez ahí tenga su lugar la atopía (Barthes 2002a, IV, pp. 231-232). Es el momento y el espacio del ego, incluyendo la relación con los otros. Esta posición es matizada en Roland Barthes par Roland Barthes (2002a, IV, p. 717). Nuestro autor preconiza un hedonismo radical, pero no absoluto. Más adelante, lo someterá a una severa crítica. En cualquier caso, debemos cuidarnos de identificarlo con el egoísmo racional y/o asociarlo al fascismo social. Tal asimilación podría realizarse, como hizo Pasolini en su película Salò o le 120 giornate di Sodoma (1975) con Sade, Fourier, Loyola, leyendo literalmente a Sade y prescindiendo de Fourier y de Loyola. Con ser radical, el hedonismo de Barthes, declaradamente epicúreo, está matizado por otras filosofías. En sus palabras, «il pourrait dire qu'il réunit en lui contradictoirement toutes les philosophies païennes de la décadence: le pyrrhonisme, le stoïcisme, l'épicuréisme, l'asianisme» (Barthes 2010, p. 317).

\section{3 CONTRACTUALISMO}

En Le lexique de l'auteur, Barthes (2010, pp. 203-208) subraya la importancia que, en su pensamiento y su experiencia personal, adquiere el contrato, con un papel no desdeñable, aunque no muy visible, en la obra. A través de esta, evocando algunos puntos álgidos, revisa sus posicionamientos frente al contrato: neutral, interpreta el contrato como categoría; negativo, en contra, critica el contrato como reificación del intercambio; positivo, a favor, postula el contrato como régimen de convivencia. En ese paso, Barthes alude a la democracia como «régime idéal du contrat social» (2010, p. 206). Su reflexión sobre el contrato abarca, denosta y vindica, dimensiones y aspectos tanto sociales como individuales. Haciendo balance de pros y contras, adopta una posición contractualista. Sin embargo, de toda esta reflexión, pasa poco, apenas unas líneas de resumen y un breve fragmento, a Roland Barthes par Roland Barthes (2002a, IV, pp. 638-639), donde nuestro autor hace un «elogio ambiguo» del contrato. El campo privilegiado serían las relaciones humanas, 
es decir, los contactos inter-personales y nuestro autor presenta como modelo el «contrato de prostitución». Este escenario parece situarnos ante un contrato (sexual, y no solo) libertario (Belliotti 2010, p. 439). El equívoco se deshace si regresamos al seminario. Barthes (2010, pp. 206-207) piensa ese contrato, referido a un intercambio sin dinero por medio, según el modelo libertino: abierto, basado en el acuerdo entre las partes y orientado a la satisfacción recíproca. El sexo solo ofrece un modelo, para marcar unos rasgos (acuerdo, igualdad y reciprocidad) en las relaciones inter-personales. Por lo demás, Barthes remite este contrato personal al contexto, y modelo, del contrato social y la democracia «ginebrina»(2010, p. 207), recordando un artículo suyo sobre Saussure, como ejemplo de contractualismo, no solo lingüístico sino, analógicamente, también social, democrático, al modo de Rousseau (Barthes 2002a, IV, p. 333).

\section{4 PREFERENCIALISMO}

Imagina Barthes (2002a, IV, p. 731), conduciendo un día de verano, en 1970, entre Salamanca y Valladolid, una filosofía nueva, que bautiza como «preferencialismo», consistente en la elección de lo preferible y la satisfacción de las preferencias en un mundo que se ofrece como plural. Mi duda al leer esta «propuesta» es si Barthes no sabe que esta filosofía existe e incluso tiene las dimensiones de una escolástica en el pensamiento ético y político contemporáneo: el utilitarismo. ¿Está Barthes jugando con el lector o, de verdad, ignora la existencia del preferencialismo? En mi opinión, no habría ningún problema en que lo ignorase: somos seres limitados y el campo del saber es infinito. Pero, puede no ignorarlo y estar haciendo un guiño. En todo caso, el preferencialismo tal como lo formula Barthes excluye el egoísmo racional: es una teoría de la elección, ética y política, basada en la inclinación, una adhesión ni dogmática ni violenta, con una remota connotación amorosa. En esos términos se expresará en la aclaración que hace sobre el preferencialismo (Barthes 2002a, V, pp. 485-486), publicada originalmente en El País, el 28 de enero de 1979 (Sirvent 2015, p. 8). En concreto, entiende por preferencia: «la nuance, l'engagement prudent, mesuré, révocable» (Barthes 2002a, V, p. 485). El preferencialismo es importante, también, porque Barthes lo presenta como una filosofía opuesta a «toutes les dogmatismes, c'est-à-dire, à toutes les philosophies qui parlent comme si elles détenaient la vérité, et notamment, pour parler des plus récentes: le marxisme et la psychanalyse» (2002a, V, p. 485). En suma, contra la presión política y ética que, estos y otros sistemas, pueden ejercer sobre el individuo.

\section{FiLOSOFÍA: ÉTICA}

La filosofía espontánea que acabamos de caracterizar, a partir de la 
auto-reflexión de Barthes en 1975, posee unos trazos (utopismo, hedonismo, contractualismo, preferencialismo) marcadamente éticos, propios de una ética. Ese es el marco, la ética, en el que, de ahí en adelante ${ }^{15}$, se va a encuadrar su trabajo. Nuestro autor, que llega a definirse como filósofo ${ }^{16}$, coloca su magisterio, al concluir el primer curso, en 1977, en el Collège de France, en el campo de la ética (Barthes 2002b, p. 184). Con Fragments d'un discours amoureux (1977), comienza una reflexión proseguida hasta el final de sus días en cursos, seminarios y publicaciones. El tema nuclear es el sujeto, es decir, el individuo, contemplado en la interrelación con el otro y los otros. No se trata del contacto o los contactos interindividuales, sino de la interacción interpersonal que mantiene una relación intersubjetiva, que puede tomar la forma de una convivencia y dar lugar a la constitución de una comunidad. El nexo es el sentimiento o afecto. Barthes examina una modalidad extrema: el amor en su confluencia con la muerte ${ }^{17}$. Esta reflexión culmina en su último libro, La chambre claire (1980). En esos años, entre 1975 y 1980, Barthes realiza una indagación ética acerca de patrones de acción y modos de vida, teniendo como sujeto el individuo singular en su relación con los demás, en los ámbitos privado y público, bajo la mediación de poderes varios. En este contexto, el propio Barthes, su experiencia y su pensamiento, se convierte en objeto de su inquisición ética. Y, con ello, su filosofía espontánea es sometida a la criba, al juicio, de la reflexión filosófica. Veamos, sucintamente, cómo la ética que Barthes formula y desarrolla ${ }^{18}$ afecta a su filosofía espontánea y modifica o trastoca sus rasgos. De paso, podremos ofrecer una idea, siquiera mínima, de su aportación a la ética.

\section{1 Utopismo / EUdEMONISMO}

En términos generales, Barthes mantiene la perspectiva utópica, pero menos escatológica y más pragmática. En la lección inaugural en el Collège de France, impartida el 7 de enero de 1977, retoma y reivindica su concepción de la literatura como utopía del lenguaje, como tarea asociada a la acción de cambiar la vida (Barthes 2002a, V, p. 436). En estos años, publica con intención reivindicativa. Así, vindica: el discurso amoroso (Barthes 2002a, V, pp. 27, 32), la literatura, Sollers como escritor y como intelectual (Barthes 2002a, V, pp. 619-620). Significativamente, en La chambre claire, selecciona

15 De ahí en adelante y desde atrás: «Toda una ética de la escritura» (Marinas 2007).

16 «Je dirai d'une façon plus radicale: difficile (pour moi) de supporter la vie sans y philosopher (s'étourdir accroîtrait le malheur)» (Barthes 2003, p. 285).

17 Mors-Amor (Seabra 1982, pp. 10-14).

18 En la línea de «moralistas» como La Bruyère y La Rochefoucauld, ambos estudiados por Barthes (2002a, II, pp. 473-487 y IV, pp. 25-40). Cfr. Coste 1998. 
fotos de nítida connotación (y reivindicación) política: por ejemplo, contra la dictadura en Nicaragua (Barthes 2002a, V, pp. 806, 808), contra el esclavismo (Barthes 2002a, V, pp. 816, 853-854). Sin embargo, ahora el utopismo, sin dejar de fundarse en la justicia y de preconizar el bienestar, se enmarca e inscribe en un eudemonismo (Barthes 2002b, pp. 177-178). Lo que Barthes pone en valor y está en juego es la felicidad, como bien asequible y realizable. Pero, asimismo, como un bien perecedero, pasado y perdido. De ahí, un eudemonismo trágico.

\section{2 Hedonismo / Altruismo}

En La chambre claire, Barthes critica y se desembaraza del placer y el hedonismo. En ese texto, hace explícita, y radicaliza, una posición que viene de antes, patente ya en su vindicación del sentimiento y su postulación del afecto. Nuestro autor abandona el hedonismo porque considera que el placer no es un buen conductor del conocimiento ni, tampoco, un buen criterio para la actuación. Para Barthes (2002a, V, p. 836), el placer es un mediador imperfecto porque no permite acceder a la universalidad, al conocer, ni a la singularidad, al actuar. El placer, como criterio de evaluación, lleva a no percibir al otro, o a prescindir de él, en la acción y la relación. Para un sujeto hedonista, los demás, incluidos los más próximos, solo cuentan como objetos de cálculo. Bajo la mediación del placer, el otro no existe, no tiene la consideración de sujeto, aparece apenas como un objeto. Es preciso colocar otras experiencias en la mediación, concretamente el amor y la muerte (Barthes 2002a, V, p. 849), para que, en las relaciones, puedan aparecer, y contar, las cualidades, como la bondad, y el otro mismo, la persona (Barthes 2002a, V, pp. 845, 853). El placer es un bien que reconforta al sujeto, pero hay otros bienes, las virtudes, que hacen aparecer al otro, como par que trastoca al sujeto y lo coloca en una interrelación. El otro aparece en el fundamento y el horizonte del sentido. Es decir, de la existencia y la acción. Por ello, hablamos de altruismo.

\section{3 Contractualismo / COMUnitarismo}

Barthes matiza su asunción del contractualismo, tras ahondar en el vínculo comunitario. En su formulación del contractualismo, Barthes defendía (el valor de) lo convencional, producto del acuerdo, como la ciudadanía democrática, frente a lo natural, lo dado por la naturaleza, como la filiación (Barthes 2002a, IV, p. 330). Ahora, esta misma y otros nexos, relacionables con la naturaleza humana, pueden estar en la base de la formación de comunidades. Barthes mantiene su adhesión al contractualismo a escala social global, como principio de organización política de la vida social en la forma de una democracia, pero matiza su aplicación en el ámbito de las relaciones interpersonales, aquellas que pueden dar lugar a la formación de comunidades dentro y fuera de la casa. 
En estas comunidades, las que se constituyen para «vivir juntos», es básica y nuclear la afinidad, no circunstancial, sino acerca de los fines de la vida (Barthes 2002b, pp. 78-84). En otras palabras, estas comunidades nacen y se nutren de la participación en una concepción y una vivencia del bien. En su seno, en alguna, puede darse el soberano bien (Barthes 2002a, V, p. 847).

\section{4 PREFERENCIALISMo / EXISTENCIALismo}

Como sucede con el hedonismo, Barthes somete también a una severa corrección al preferencialismo. Lo contextualiza y subordina en un marco mayor y rector: el existencialismo. Somete las elecciones (el preferencialismo) a la elección (existencialista). Esta es la elección radical: escoger entre la existencia auténtica y la inauténtica. En palabras de Barthes (2002a, V, p. 885), elegir entre afrontar la realidad o vivir en la ilusión, la alienación y el gregarismo. Afrontar la realidad es hacerse cargo de la existencia y de lo existente, tal y como aparecen al revelarse, en el ser humano y en todo ser vivo, su condición temporal, pasajera y perecedera: en suma, su mortalidad. ${ }^{19}$ Para Barthes, la tarea es testimoniar, por medio de la escritura. Quizá de una novela (Barthes 2003, pp. 377-384). De hecho, por medio de la filosofía: $L a$ chambre claire. ${ }^{20}$ Inscribe ese testimonio en una tentativa de contestación a la sociedad occidental contemporánea (Barthes 2002a, V, pp. 865, 883-885).

\section{CONCLUSIONES}

Para dilucidar la relación de Barthes con la filosofía, hemos partido de su propia obra, trazando cuatro surcos proporcionados por nuestro autor: los ecos, los intertextos, la filosofía espontánea y la moralidad o ética. Sin embargo, al desarrollar nuestra indagación, hemos seguido líneas originales y señalado rasgos, si no inéditos, poco resaltados en la recepción crítica.

Así, en los ecos y el intertexto, donde Barthes indica sus conexiones con la filosofía contemporánea, hemos explorado, y mostrado, (1) el enraizamiento y (2) la relación de su pensamiento con la filosofía clásica, en concreto, con Aristóteles.

En su filosofía espontánea, apuntamos algunos rasgos poco frecuentes, subrayando (3) que se trata, fundamentalmente, de una ética. Y, por último, adentrándonos en su última fase, la moralidad, hemos esbozado unas líneas generales de (4) su posición, sin entrar en su contribución, en la ética contemporánea.

Además, a lo largo de esta indagación, hemos puesto de relieve (5) que Barthes, no sin titubeos o con modestia, se definió a sí mismo como filósofo.

19 Piedad, Nietzsche (Barthes 2002a, V, p. 883).

20 Barthes (2002a, V, p. 785) dedica este libro a Sartre. 


\section{REFERENCIAS BIBLIOGRÁFICAS}

ALTHUSSER, L. 1974: Philosophie et philosophie spontanée des savants (1967). Paris: François Maspero.

ARISTÓTELES, 1985: Ética a Nicómaco, edición bilingüe y traducción de Julián Marías y María Araújo. Madrid: Centro de Estudios Constitucionales.

ARISTÓTELES, 1990: Retórica, edición bilingüe y traducción de Antonio Tovar. Madrid: Centro de Estudios Constitucionales.

ARISTÓTELES, 1999: Poética, edición bilingüe e tradución galega de F. González Muñoz. A Coruña: Biblioteca-Arquivo Teatral «Francisco Pillado Mayor».

AUBENQUE, P. 1993: "Aristote et la démocratie», in Aubenque, P. (dir.) \& Tordesillas, A. (ed.), Aristote politique. Études sur la Politique d'Aristote, pp. 255-264. Paris: PUF.

BARTHES, R. 2002a: Euvres complètes, I (1942-1961), II (1962-1967), III (19681971), IV (1972-1976) \& V (1977-1980), édition d'Éric Marty. Paris: Seuil.

BARTHES, R. 2002b: Comment vivre ensemble: simulations romanesques de quelques espaces quotidiens. Cours et séminaires au Collège de France (19761977), texte établi, annoté et présenté par Claude Coste. Paris: Seuil-Imec.

BARTHES, R. 2002c: Le neutre. Cours au Collège de France (1977-1978), texte établi, annoté et présenté par Thomas Clerc. Paris: Seuil-Imec.

BARTHES, R. 2003: La préparation du roman I et II. Cours et séminaires au Collège de France (1978-1979 et 1979-1980), texte établi, annoté et présenté par Nathalie Léger. Paris: Seuil-Imec.

BARTHES, R. 2010: Le lexique de l'auteur. Séminaire à l'École pratique des hautes études 1973-1974. Suivi de Fragments inédits du Roland Barthes par Roland Barthes, avant-propos d'Éric Marty, présentation et édition d'Anne Herschberg Pierrot. Paris: Seuil.

BELLIOTTI, R.A. 2010: «La sexualidad», in Singer, P. (ed.), Compendio de ética, pp. 433-448. Madrid: Alianza.

CALVET, L.J. 1973: Roland Barthes. Un regard politique sur le signe. Paris: Payot.

CALVET, L.J. 1990: Roland Barthes. Paris: Flammarion.

COSTE, C. 1998 : Roland Barthes moraliste. Ville Neuve d'Asq: Presses Universitaires du Septentrion.

DERRIDA, J. 1981: «Les morts de Roland Barthes»: Poétique 47, pp. 269-292. Paris: Seuil.

DUFRENNE, M. 1981: «Du signifiant au référent»: Revue d'Esthetique 2 «Sartre/ Barthes», pp. 71-82. Toulouse: Pensée/Privat.

MARCUSE, H. 2007: One-Dimensional Man. Studies in the ideology of advanced industrial society. London and New York: Rouledge Classics. Edición original: 1964.

MARINAS, J.M. 2006: «Barthes, gran reserva: Ética de los signos masivos»: Agora 24/1, pp. 53-63. Santiago de Compostela: Universidade de Santiago de Compostela. 
MARINAS, J.M. 2007: «Toda una ética de la escritura», in Roland Barthes, El placer del texto. Lección, pp. IX-XXIII. Madrid: Siglo XXI.

MILNER, J.C. 2003: Le pas philosophique de Roland Barthes. Paris: Verdier.

MORIARTY, M. 1991: Roland Barthes. Cambridge: Polity Press.

PINO ESTIVILL, E. 2018: Circulación de textos y usos de Roland Barthes en la crítica literaria francesa, española y argentina (1965-2015). Barcelona: Universitat de Barcelona.

RECKERT, S. 1982: «Império dos signos ou imperialismo dos significantes?», in VV. AA., Leituras de Barthes, pp. 57-66. Lisboa: Publicações Dom Quixote.

ROGER, Ph. 1986: Roland Barthes, roman. Paris: Grasset.

RUBINO, G. 1984: L'intellettuale e i segni. Saggi su Sartre e Barthes. Roma: Edizioni di Storia e Letteratura.

SALAZAR, Ph.-J. 1993: «Barthes et Aristote», in Coquio, C. \& Salado, R. (eds.), Barthes après Barthes. Une actualité en questions, pp. 113-116. Pau: Publications de l'Université de Pau.

SAMOYAULT, T. 2015: Roland Barthes. Paris: Seuil.

SEABRA, J.A. 1982: Mors-Amor (Paixão de Barthes). Porto: Nova Renascença.

SIRVENT RAMOS, Á. 2015: «La recherche barthésienne en Espagne jusqu'à 2014», Revue Roland Barthes, n², octobre 2015, «Barthes à l'étranger», pp. 1-44. Paris. https://www.roland-barthes.org/revue.html.

SOTO, L. G. 2015: Barthes filósofo. Vigo: Galaxia.

STAFFORD, A. 2015: «Et tout le reste est littérature», Barthes Studies, nº 1, pp. 148152. Cardiff. http://sites.cardiff.ac.uk/barthes/article/book-review-et-tout-lereste-est-litterature/

STAFFORD, A. 2017: «Roland Barthes Dialectician? In the Final Instance?», Barthes Studies, $\mathrm{n}^{\circ} 3$, pp. 97-120. Cardiff. http://sites.cardiff.ac.uk/barthes/article/rolandbarthes-dialectician-in-the-final-instance/

Luis García Soto es Profesor de Filosofía Moral, Facultade de Filosofía, Universidad de Santiago de Compostela

Líneas de Investigación:

Paradigmas de la Filosofía Moral, Posestructuralismo y Posmodernidad, Filosofía y Literatura, Filosofía y Paz, Justicia Política, Filosofía Moral y Política en Galicia, Bioética

Publicaciones recientes:

(2019): «Ética, Política e Democracia: Seguindo Aristóteles, Kant e Mill», Revista Portuguesa de Filosofía 75(1), pp. 305-338.

(2018): «Barthes: novela y filosofía, en el medio de la vida», Postrepsis. Revista de Filosofia 14, pp. 55-69.

Correo electrónico: luisg.soto@usc.es 